\title{
Disentangling Emotion Processes in Borderline Personality Disorder: Physiological and Self-Reported Assessment of Biological Vulnerability, Baseline Intensity, and Reactivity to Emotionally Evocative Stimuli
}

\author{
Janice R. Kuo \\ Stanford University \\ Marsha M. Linehan \\ University of Washington

\begin{abstract}
This study investigated M. Linehan's (1993) theory that individuals meeting criteria for borderline personality disorder (BPD) have high biological vulnerability to emotion dysregulation, including high baseline emotional intensity and high reactivity to emotionally evocative stimuli. Twenty individuals with BPD, 20 age-matched individuals with generalized social anxiety disorder (SAD), and 20 agematched normal controls ( $\mathrm{NCs}$ ) participated in 2 separate emotion induction conditions, a standardized condition, and a personally relevant condition. Respiratory sinus arrhythmia (RSA), skin conductance response (SCR), and self-report measures were collected throughout the experiment. BPD participants displayed heightened biological vulnerability compared with NCs as indicated by reduced basal RSA. BPD participants also exhibited high baseline emotional intensity, characterized by heightened SCR and heightened self-reported negative emotions at baseline. However, the BPD group did not display heightened reactivity, as their physiological and self-reported changes from baseline to the emotion inductions tasks were not greater than the other 2 groups.
\end{abstract}

Keywords: borderline personality disorder, emotion regulation, vulnerability, reactivity, psychophysiology

Borderline personality disorder (BPD) is a life-threatening disorder characterized by severe cognitive, behavioral, and emotional dysregulation. The prevalence of BPD in the general population is between $1 \%$ and 5.9\% (Grant et al., 2008; Samuels et al., 2002; Swartz, Blazer, George, \& Winfield, 1990; Torgerson, Kringlen, \& Cramer, 2001), and up to $40 \%$ of high utilizers of inpatient mental health care services (Geller, 1986) and approximately $15 \%$ of outpatients are diagnosed with BPD (Koenigsberg, Kaplan, Gilmore, \& Cooper, 1985; Torgerson et al., 2001; Widiger \& Weissman, 1991). The implications of these statistics are compelling in view of the extremely high lifetime prevalence of self-injurious acts (up to 84\%; Clarkin, Widiger, Frances, Hurt, \& Gilmore, 1983; McGlashan et al., 2005), the rate of suicide attempts (over $70 \%$ of BPD patients; Soloff, Lynch, \& Kelly, 2002; Soloff, Lynch, Kelly, Malone, \& Mann, 2000; Zisook, Goff, Sledge, \& Schuchter, 1994), and the $10 \%$ suicide rate (Frances, Fyer, \& Clarkin, 1986; Paris, Brown, \& Nowlis, 1987).

Dialectical behavior therapy (DBT) is at present the most empirically supported treatment for BPD (see Lieb, Zanarini, Linehan, \& Bohus, 2004) and is based on Linehan's (1987) theory of emotion dysregulation as the core characteristic of the disorder. Linehan (1993) proposed a biosocial developmental model, which states that BPD criteria are caused jointly by a biological vulner-

Janice R. Kuo, Department of Psychology, Stanford University; Marsha M. Linehan, Department of Psychology, University of Washington.

Dr. Linehan receives royalties from Guilford Press for books she has written on dialectical behavior therapy (DBT) and also receives DBT training fees and royalties for DBT training materials from Behavioral Tech, LLC.

Correspondence concerning this article should be addressed to Janice R. Kuo, Department of Psychology, Stanford University, Stanford, CA 94305. E-mail: jrkuo@stanford.edu ability to emotion dysregulation and an invalidating environment (one that arbitrarily negates, rejects, or dismisses an individual's behavior). According to Linehan's model, emotion dysregulation in BPD includes high baseline negative emotional intensity as well as high emotional reactivity, which refers to changes in intensity of emotional responding after presentation of an emotionally evocative cue. High emotional intensity and reactivity are proposed to be sequelae of emotional vulnerability, and emotion dysregulation occurs as the individual is further unable to modulate the intensity of the emotional response effectively. When the emotionally vulnerable individual is placed in a chronically invalidating environment, the constant transaction between the two leads to the subsequent development of BPD.

There is a growing body of research in which Linehan's (1993) proposed factors of emotion dysregulation in BPD are examined as well as the biosocial model in which it is based (see Rosenthal et al., 2008, for a review). The high intensity and high reactivity components of emotion dysregulation have been examined in several studies. In contrast, the biological dimension of the biosocial model, which specifies that BPD individuals are biologically vulnerable to emotion dysregulation, has been examined in fewer studies. Indeed, little is known about the biological factors that render a BPD individual vulnerable to emotional intensity and reactivity and, more broadly, to emotion dysregulation. The review below focuses on biological vulnerability, baseline emotional intensity, and emotional reactivity in BPD, the limitations of the research to date, and the rationale for the present study.

\section{LINEHAN'S BIOSOCIAL THEORY: BIOLOGICAL VULNERABILITY}

Various biological factors that may influence the development of BPD have been identified in over two decades of research. 
Studies of neurotransmitter dysfunction, particularly within the serotonergic system, suggest a link between reduced serotonergic activity and impulsivity in BPD (see Gurvits, Koenigsberg, \& Siever, 2000, for a review; Ni et al., 2006). Electrophysiological studies in BPD (see Boutros, Torello, \& McGlashan, 2003, for a review) have reported abnormal brain electrical activity such as electroencephalography (EEG) slowing, lower EEG vigilance (Hegerl et al., 2007), increased rapid eye movement (REM) density (Battaglia, Ferini Strambi, Bertella, Bajo, \& Bellodi, 1999), decreased REM latency (Battaglia et al., 1993), and reduced righthemisphere gamma phase synchrony (Williams, Sidis, Gordon, \& Meares, 2006), which together have been proposed to contribute to the impulsiveness and affective lability associated with the disorder. More recently, structural imaging studies have reported decreased hippocampal and amygdala volume in BPD (Driessen et al., 2000; Schmahl, Vermetten, Elzinga, \& Bremner, 2003; Tebartz van Elst et al., 2003). Altered baseline metabolism in prefrontal regions as well as dysfunctional frontolimbic networks in BPD have been identified in functional imaging studies (see Schmahl \& Bremner, 2006) in response to stressful challenges. Although these reported aberrations have been proposed as biological markers associated with BPD criteria, what remains unclear is whether these factors reflect a specific vulnerability to emotion dysregulation, the central mechanism proposed by Linehan's model.

Recent evidence has linked vagal tone, referring to parasympathetic influence on the heart, with emotion regulatory processes. Porges' polyvagal theory (Porges, Doussard-Roosevelt, \& Maiti, 1994) suggests that activation of the myelinated vagal system terminating at the sinoatrial node of the heart is positively associated with various attentional and emotion regulatory processes. Substantial literature suggests that basal vagal tone is associated with individual differences in emotional vulnerability (Beauchaine, 2001; Butler, Wilhelm, \& Gross, 2006; Porges, 1995a, 1995b). Additionally, studies of adult clinical samples have reported reduced basal vagal tone in several Axis I disorders (Cohen et al., 2000, 1998; Friedman \& Thayer, 1998; Lyonfields, Borkovec, \& Thayer, 1995; Rechlin, Weis, Spitzer, \& Kaschka, 1994; Thayer, Friedman, \& Borkovec, 1996), which has been conceptualized as indicating difficulties in effectively interacting emotionally with the environment. Collectively, these findings have led many investigators to conceptualize basal vagal tone as an index of biological vulnerability to emotion dysregulation. Despite such evidence, few researchers have investigated vagal tone in BPD.

\section{LINEHAN'S EMOTION DYSREGULATION THEORY: HIGH BASELINE INTENSITY AND HIGH REACTIVITY}

\section{High Intensity}

The primary method for assessing heightened emotional intensity in BPD has been through self-report questionnaires. Consistent with Linehan's theory, these studies have reported higher negative emotional intensity in BPD compared with nonclinical controls, other Axis II individuals, as well as individuals with bipolar disorder (Henry et al., 2001; Koenigsberg et al., 2002; Levine, Marziali, \& Hood, 1997). Other studies have reported a positive correlation between negative emotional intensity and BPD features
(Cheavens et al., 2005; Rosenthal, Cheavens, Lejuez, \& Lynch, 2005; Yen, Zlotnick, \& Costello, 2002) as well as intense negative emotions following social interactions (Russell, Moskowitz, Zuroff, Sookman, \& Paris, 2007). Ambulatory monitoring studies indicate that BPD participants report higher unpleasant emotional intensity (Ebner-Priemer et al., 2007; Stein, 1996) and higher aversive tension (Stiglmayr et al., 2005) than nonclinical participants in a naturalistic context.

The self-report studies provide substantial evidence for subjective, heightened negative emotional intensity in BPD. These data are commonly interpreted as evidence for heightened emotional reactivity in BPD. As noted above, however, Linehan's model defines high reactivity as stimulus-related changes in emotional intensity. Although self-report studies provide evidence of highnegative emotional intensity in BPD, these studies do not directly assess changes in emotional intensity after presentation of an emotionally evocative stimulus (hence, reactivity). Indeed, a major limitation in the self-report literature is that baseline intensity and reactivity are often confounded. Thus, it remains unclear whether such self-reported intensity in BPD is indeed due to increased reactivity, increased baseline levels of emotional intensity, or both.

\section{High Reactivity}

In contrast to the self-report studies, reactivity has been assessed more directly in physiological studies. However, findings from this literature are mixed. Herpertz and colleagues published three physiological emotion studies (Herpertz, Kunert, Schwenger, \& Sass, 1999; Herpertz et al., 2000, 2001) in which BPD participants viewed neutral, positive, and negative valenced slides while being physiologically monitored. There were no indications of heightened emotional reactivity in BPD. It is interesting to note that in the first two studies (Herpertz et al., 1999; Herpertz et al., 2000), BPD individuals exhibited significantly lower skin conductance (SC) magnitude, a measure of sympathetic activity, across all slide valences compared with the control groups, suggesting lower intensity of emotional responding across the task. Similarly, in a study in which abused women with BPD, posttraumatic stress disorder (PTSD), or neither disorder listened to personally relevant abandonment and abuse scripts, Schmahl et al. (2004) found a tendency toward greater SC responses to the abandonment script in the BPD group, although this did not reach the level of significance.

In contrast, studies by Ebner-Priemer (Ebner-Priemer et al., 2005, 2007) offer support for physiological reactivity in BPD. Ebner-Priemer et al. (2007) found that nonmedicated BPD individuals exhibited a heightened degree of emotional heart rate (i.e., changes in heart rate that are devoid of movement influences) compared with healthy controls in an ambulatory monitoring paradigm. Ebner-Priemer et al. (2005) also reported larger startle response magnitude (i.e., higher reactivity) and slower habituation in BPD compared with psychologically healthy controls. In this study, the investigators also compared differences in physiological responding between BPD participants high and low in presentstate dissociation. Results indicated that BPD participants with low present-state dissociation exhibited higher EMG responses than BPD participants high in present-state dissociation.

One study to date has assessed vagal withdrawal as an indicator of emotional reactivity in BPD. According to Porges' polyvagal 
theory (Porges, Doussard-Roosevelt, Portales, \& Greenspan, 1996), the appropriate use of the "vagal brake" is essential for proper engagement with tasks that require attention, social interaction, and emotion regulation. Consistent with this theory, recent evidence suggests that excessive vagal withdrawal reflects heightened emotional reactivity or emotionally dysregulated states such as panic (Yeragani et al., 1990), anger (Donzella, Gunnar, Krueger, \& Alwin, 2000), worry (Lyonfields et al., 1995; Thayer et al., 1996), and hyperarousal in response to traumatic memories (Sack, Hopper, \& Lamprecht, 2004).

Austin, Riniolo, and Porges (2007) monitored respiratory sinus arrhythmia (RSA), an index of vagal tone, and heart period (HP) while BPD participants and nonclinical controls watched film clips. Although there were no baseline differences, the BPD group displayed a decrease in RSA and HP, whereas the control group displayed the opposite pattern throughout the course of the experiment. Austin et al. interpreted the vagal withdrawal exhibited by the BPD participants as heightened emotional reactivity. However, it is unclear whether the vagal withdrawal exhibited by the BPD participants was stimulus-linked (i.e., in response to the films) or due to the passage of time. Additionally, Austin et al. excluded BPD participants with any additional disorders. Given that the rates of comorbidity between BPD and other disorders is as high as 98\% (see Skodol et al., 2002, for a review), generalizability of these results is limited.

In summary, although the physiological literature provides some evidence for heightened emotional reactivity in BPD, the findings within this literature are mixed and fraught with limitations. The mixed findings can be accounted for by the variability in the stimuli used across investigations. Some studies included standardized stressors (e.g., slides) and others idiographic stressors (e.g., abandonment scripts). The discrepant methodologies make it difficult to determine whether BPD individuals are more reactive to certain cues or whether other methodological factors are influencing the results. Incorporating both standardized and idiographic stimuli under one methodological umbrella is needed to address this question. A second limitation is that very few of these studies have included clinical comparison groups. Given the recent movement toward a unifying theory of emotion dysregulation in Axis I disorders (Barlow, Allen, \& Choate, 2004), additional comparisons of the emotion dysregulation profile in BPD versus other Axis I disorders is warranted. A majority of studies have also failed to control for the impact of dissociation on results, despite evidence indicating that present-state dissociation mitigates autonomic output in BPD (Ebner-Priemer et al., 2005). Finally, there has been a lack of comprehensive autonomic assessments in the physiological studies to date. Contemporary views of autonomic activity emphasize that contributions of the sympathetic nervous system (SNS) and the parasympathetic nervous system (PNS) may vary reciprocally, coactively, or independently (Berntson, Cacioppo, \& Quigley, 1991), and therefore simultaneously assessing SNS and PNS activity is crucial to understanding emotional processing systemically.

\section{The Present Study}

We examined three core components of Linehan's model (biological vulnerability, baseline emotional intensity, and emotional reactivity) and addressed the limitations of previous research.
Three groups of participants-BPD, generalized social anxiety disorder (SAD), and normal controls (NCs) - engaged in a standardized (films) and idiographic (imagery) paradigm while being physiologically monitored. The rationale for selecting SAD as a clinical control was as follows: First, given the substantial evidence for emotion dysregulation in anxiety disorders, selecting an anxiety disorder control group would allow for comparisons between BPD and other groups in which emotion dysregulation processes have been indicated. Second, given the high (approximately 56\%) comorbidity of BPD with PTSD (Zanarini et al., 1998), selecting a PTSD control group would limit the specificity between the two samples. Furthermore, given the existing theoretical debate around generalized anxiety disorder (GAD) as a separate diagnostic category, as indicated by its high comorbid rates with depression as well as other anxiety disorders (see Nutt, Argyropoulos, Hood, \& Potokar, 2006), selecting this group as a clinical control would also limit the specificity between the two samples. Indeed, the "diagnostically unclean" GAD group would render it difficult to ascertain what clinical conditions BPD is distinct from. SAD was decidedly the most appropriate clinical control group because (a) it would allow for comparability with the present data on emotion processes in SAD and anxiety disorders in general, (b) its rate of comorbidity with BPD (45\%-50\%; Zanarini et al., 1998; Zanarini, Frankenburg, Hennen, \& Silk, 2003) is lower than that of PTSD and depression, and (c) its diagnostic profile is more distinctive than that of GAD.

The primary hypotheses were as follows: (a) BPD individuals would exhibit biological vulnerability to emotion dysregulation as indicated by reduced basal RSA compared with the SAD and NC groups; (b) BPD individuals would demonstrate heightened baseline negative emotional intensity compared with the SAD and NC groups as indicated by higher electrodermal responding and higher self-reported negative emotions at baseline and (c) BPD individuals would exhibit heightened emotional reactivity compared with the SAD and NC groups as indicated by greater changes from baseline to emotion-eliciting tasks in physiological and self-report measures.

The limitations reviewed above were addressed by first examining Linehan's largely untested notion of biological vulnerability in BPD by comparing baseline differences in vagal tone. Second, baseline negative emotional intensity and stimulus-induced reactivity were separately assessed, thus allowing the two constructs to be delineated. Emotional reactivity was assessed across three core emotions (sadness, anger, and fear) and across both standardized and personally relevant conditions. The addition of a clinical control group, SAD, allowed for comparisons of the BPD emotion dysregulation profile with that of another clinical population. Additionally, dissociative state was controlled for, and both sympathetic and parasympathetic indices were measured.

\section{Method}

\section{Participants}

Three groups of participants were recruited to take part in the study: individuals with BPD, individuals with SAD, and individuals with no current Axis I disorders or BPD (NC). Participants were recruited through flyers and Internet postings throughout the community, local hospitals, and clinics, and by outreach to BPD participants 
in existing treatment studies at the University of Washington Behavioral Research and Therapy Clinics (UWBRTCs). Only women were recruited because of indicated differences in emotional reactions (Fischer, 2000) as well as differences in cardiovascular control and vagal activity between genders (Fyan et al., 1994). Given the challenges of diagnosing young children with personality disorders, only participants over the age of 18 were included. Exclusion criteria included schizophrenia, schizophreniform, schizoaffective disorders, psychosis nonspecified, bipolar disorder, current substance dependence, as well as the following physical conditions: epilepsy or seizure disorder, heart disease, and asthma. Participants were also excluded if they were taking any psychotropic medication other than selective serotonin reuptake inhibitors (SSRIs), major tranquilizers, antihistamies, or beta blockers. Colorblindness was also an exclusion criterion, as one of the baseline tasks in the study required the identification of colors. Finally, SAD and NC participants meeting four or more BPD criteria or the impulsivity and self-harm/suicidality criteria from the Structured Clinical interview for DSM-IV Axis II (SCID-II) BPD section (First, Spitzer, Gibbons, Williams, \& Benjamin, 1996) were excluded to ensure the three samples remained distinct. Seventeen SAD and NC participants were therefore excluded after screening based on these criteria. All participants were between ages 18 and 45 years and were matched on age ( \pm 2 years). The final sample resulted in $20 \mathrm{BPD}, 20 \mathrm{SAD}$, and $20 \mathrm{NC}$ participants. Effect sizes from pilot data as well as other physiological studies with similar designs suggested that, with a sample of 20 in each group, there would be a power of .68 to detect baseline physiological differences as well as a power of .85 to detect differences in reactivity.

\section{Participant Demographics}

Mean age for the three groups were as follows: $\mathrm{BPD}=23.55$ years, $\mathrm{SAD}=23.90$ years, $\mathrm{NC}=23.30$ years, indicating successful matching. See Table 1 for ethnic and marital demographics and Table 2 for rates of Axis I comorbidiy for the BPD and SAD groups. A Mann-Whitney test indicated that there was not a significant difference in the number of comorbid diagnoses between the BPD and SAD groups, with an average rank of 21.42 for the BPD group and 17.7 for the SAD group $(p>.05)$. Four $(20 \%)$ of the BPD participants were on SSRIs (1 on citalopram, 2 on fluoxetine, 1 on sertraline), 1 (10\%) SAD participant was on citalopram, and none of the NC participants were on psychotropic medications. There were no significant differences in the number

Table 1

Participant Ethnic and Marital Demographics: Percent Breakdown

\begin{tabular}{lrrr}
\hline \multicolumn{1}{c}{ Demographic } & BPD & SAD & NC \\
\hline Caucasian & 65.0 & 72.2 & 42.2 \\
African American & 5.0 & 5.6 & 10.5 \\
Asian American & 25.0 & 16.7 & 47.3 \\
Other & 5.0 & 5.5 & 0.0 \\
Single & 84.2 & 72.2 & 84.2 \\
Married & 10.5 & 22.2 & 10.5 \\
Divorced & 5.3 & 5.6 & 5.3 \\
\hline
\end{tabular}

Note. $\mathrm{BPD}=$ borderline personality disorder; $\mathrm{SAD}=$ social anxiety disorder; $\mathrm{NC}=$ normal control.
Table 2

$B P D$ and SAD Past and Current Axis I Diagnoses:

Percent Breakdown

\begin{tabular}{|c|c|c|c|c|}
\hline \multirow[b]{2}{*}{ Diagnosis } & \multicolumn{2}{|r|}{ BPD } & \multicolumn{2}{|c|}{ SAD } \\
\hline & Past & Current & Past & Current \\
\hline Anorexia & 10 & 0 & 0 & 0 \\
\hline Bulimia & 10 & 5 & 5 & 0 \\
\hline Binge eating & 0 & 0 & 10 & 5 \\
\hline Depression & 75 & 50 & 40 & 15 \\
\hline Dysthymia & & 5 & & 0 \\
\hline Depressive NOS & 5 & 0 & 0 & 0 \\
\hline Mood disorder/medic & 5 & 0 & 5 & 0 \\
\hline Mood disorder/substance & 0 & 0 & 0 & 0 \\
\hline Substance dependence & 50 & 10 (abuse only) & 30 & 5 \\
\hline PTSD & 35 & 20 & 20 & 20 \\
\hline $\begin{array}{l}\text { Generalized anxiety } \\
\text { disorder }\end{array}$ & & 5 & & 5 \\
\hline $\begin{array}{l}\text { Obsessive-compulsive } \\
\text { disorder }\end{array}$ & 15 & 10 & 15 & 5 \\
\hline Specific phobia & 10 & 10 & 10 & 5 \\
\hline Social anxiety general & 30 & 30 & 100 & 100 \\
\hline Social anxiety eating & 5 & 5 & 0 & 0 \\
\hline Panic w/agoraphobia & 0 & 0 & 0 & 0 \\
\hline Panic & 25 & 15 & 5 & 0 \\
\hline Anxiety NOS & & 0 & & 0 \\
\hline
\end{tabular}

Note. $\mathrm{BPD}=$ borderline personality disorder; $\mathrm{SAD}=$ social anxiety disorder; NOS $=$ not otherwise specified; PTSD $=$ posttraumatic stress disorder.

of medications with an average rank of 22.00 for the BPD group and 19.00 for the SAD group $(p>.05)$.

\section{Measures}

\section{Screening and Descriptive}

The Structured Clinical Interview for Axis I DSM-IV Disorderpatient edition (First, Spitzer, Gibbon, \& Williams, 1995) and the Structured Clinical Interview for DSM-IV Axis II Personality Disorders (SCID-II)- BPD (First et al., 1996) were administered to screen for Axis I disorders and BPD, respectively. All SCIDs were conducted by the principal investigator of the study, who was trained to reliability with assessors from the larger treatment trials within the UW BRTC. The Demographic Data Survey (DDS; Linehan, 1982) was administered to obtain a wide range of demographic data, including age, height, weight, and ethnicity.

\section{Self-Report Measures of Emotion and Emotion Regulation}

Trait measures. The Difficulties in Emotion Regulation Scale (DERS; Gratz \& Roemer, 2004) was administered as a trait measure of emotion regulation. The DERS is a 36-item measure that assesses individuals' typical levels of emotion dysregulation across six domains: nonacceptance of negative emotions, inability to engage in goal-directed behaviors when experiencing negative emotions, difficulties controlling impulsive behaviors when experiencing negative emotions, limited access to emotion regulation strategies perceived as effective, lack of emotional awareness, and lack of emotional clarity. The DERS has high internal consistency $(\alpha=.93)$ and good test-retest reliability $\left(\rho_{\mathrm{I}}=.88\right)$. The 16-item 
Acceptance and Action Questionnaire (AAQ) (Hayes et al., 2004), a measure of experiential avoidance, was also administered. Finally, the State-Trait Anger Inventory (STAXI), Trait Anger subscale (Spielberger, Krasner, \& Solomon, 1988) was administered to measure trait levels of anger (Cronbach's $\alpha$ for women $=0.75$; retest correlation for women between .70 and .76).

State measures. After every baseline and emotion induction, participants reported their emotional states using the Visual Analogue Scale (VAS; Haines, Williams, Brain, \& Wilson, 1995), a measure of subjective reactions on a scale ranging from 1 to 100 on the following bipolar dimensions: relaxed-tense, calm-angry, unafraid-afraid, happy-sad, normal-unreal, relieved-uptight, contented-ashamed, and accepting-punishing. After every emotion induction, participants also completed the Dissociative State Scale (DSS; Stiglmayr, Shapiro, Stieglitz, Limberger, \& Bohus, 2001), a 21-item self-report inventory assessing the duration and intensity of acute somatic and psychological dissociation, which was included as a covariate. The scale was developed at the Borderline Research Unit, University of Freiburg, Freiburg, Germany. Test-retest reliability (1-week daily data recording, $k=.8$ ) and internal consistency estimates (Cronbach's $\alpha=0.9$ ) are high.

\section{Physiological Measures}

Respiratory sinus arrhythmia (RSA). RSA was used as the index of vagal tone and was measured by assessing the highfrequency (HF) band of spectral analysis (Berntson et al., 1997), which decomposes electrocardiogram (ECG) R-wave time series into three heart rate variability frequency ranges through Fast Fourier transformations. Spectral analyses were conducted using Mindware Technologies HRV 2.33 software (Westerville, $\mathrm{OH}$ ), which detects questionable RR intervals on the basis of the overall $\mathrm{RR}$ distribution using a validated algorithm to aid artifact detection and editing (Berntson, Quigley, Jang, \& Boysen, 1990). The lowfrequency range is less than $0.04 \mathrm{~Hz}$, mid-frequency from $0.04 \mathrm{~Hz}$ to $0.15 \mathrm{~Hz}$, and the $\mathrm{HF}$ range is greater than $.15 \mathrm{~Hz}$. Research on heart rate and heart rate variability suggest that parasympathetic/ vagal activity influences all frequencies of $<0.5$, whereas sympathetic activity affects frequencies of $<0.15$ (Berntson et al., 1997). HF spectral densities were calculated across 30-s epochs for each baseline and emotion induction.

Skin conductance response (SCR). SCR was measured as an index of sympathetic responding. Nonspecific SCRs were scored using the Mindware Technologies EDA 2.40 program, which calculated the number of fluctuations exceeding $0.05_{\mu} \mathrm{S}$ across 1-min epochs. A programmable rolling filter was used for artifact detection and editing.

All physiological measurements were collected using a BIOPAC 5-channel data acquisition system (Biopac Technologies, Model MP100, Goleta, CA). Data were digitized at 1,000 samples per second and set for a gain of 1,000 using low- $(35 \mathrm{~Hz})$ and high$(.05 \mathrm{~Hz})$ pass filters. ECG data were collected at the left and right wrists via disposable $\mathrm{Ag}-\mathrm{AgCl}$ snap electrodes (Biopac Technologies Model EL503), with a third electrode attached to the ankle for ground reference. SCR was measured by two 6-mm electrodes (Biopac model TSD203), with electrolyte gel attached to the medial phalanges of two fingers on the nondominant hand. All SC application was done according to field standards (Fowles et al., 1981).

\section{Emotion Induction Conditions}

Standardized condition/emotion films. Films known to reliably elicit targeted emotions were selected from a sample developed by Gross and Levenson (1995). Each film lasted approximately $166 \mathrm{~s}$. The sad film was a 2:51-min clip from the movie "The Champ" (Lovell \& Zeffirelli, 1979), which showed a young boy crying at his father's death. The fear film was a 3:29-min clip from the movie "Silence of the Lambs" (Saxon, Utt, Bozman, \& Demme, 1991), which depicted a basement chase scene. The anger film was a 4:06-min scene from the movie "My Bodyguard" (Devlin \& Bill, 1980), which showed a young teenage boy being bullied by another young man. Finally, the neutral film was a silent 1:30-min clip depicting colored bars. All films were presented on a 16.5 -in. $\times 12.5$-in. $(42-\mathrm{cm} \times 32$-cm $)$ computer monitor.

Personally relevant condition/imagery. Development of the imagery task followed procedures described by Pitman and colleagues (Pitman, Orr, Forgue, de Jong, \& Claiborn, 1987). Two to five days prior to the experimental procedures, participants were interviewed by a trained assessor who asked them to describe in writing the most recent or vivid event in which they felt sad, afraid, angry, and emotionally neutral (control). The assessor prompted the participant when needed in order to ensure the described event was sufficient to elicit an emotional response. Only events for which the intensity of the emotion experienced was rated as an 8 or higher on a scale of 1-10 were used. Each participant's script was then rewritten to take approximately 2 min when read out loud. In accordance with the Pitman et al. (1987) protocol, scripts were also evaluated by the trained assessor and the principal investigator to ensure that each script (with the exception of the neutral script) consisted of five emotions, five sensations, and five thoughts. The rewritten scripts maintained the exact phrases of the participants and were recorded by the principal investigator in a neutral voice tone. On the day of the experiment, the recording was played back to the participants, and they were instructed to imagine themselves back in the situation described.

\section{Procedure}

The experimental procedures were divided into two separate sessions, one for each condition. Counterbalancing procedures were applied to the order of the condition (standardized vs. personally relevant) and type of emotion induction (sadness, fear, anger, neutral). At the start of each experimental session, participants engaged in a 4-min "true baseline" in whiche they were instructed to maintain wakefulness and sit quietly and still. Participants then engaged in a 4-min "vanilla baseline" period (Jennings, Kamarck, Stewart, Eddy, \& Johnson, 1992), in which they engaged in a nonstressful, nondemanding cognitive task requiring them to count the number of times a specified color appeared on a screen. The purpose of using the vanilla baseline was to control for any negative emotions that the participant may experience during a true-baseline period.

Following the first true and vanilla baselines, participants engaged in either the standardized or the personally relevant condition, depending on the counterbalancing method. Between each emotion induction, participants engaged in a 5-min vanilla baseline. Participants were physiologically monitored throughout the entirety of the experimental session. 
All were instructed to avoid ingestion of caffeine and tobacco on the day of and refrain from taking any over the counter medications $24 \mathrm{hr}$ prior to the physiological procedures.

\section{Data Reduction and Analysis}

Analyses were conducted using SPSS, Version 13.0. A visual inspection of the physiological data indicated no distinct linear or polynomial relationship; therefore, a mixed-model analysis of variance (MMANOVA) approach was used for all physiological analysis. The mixed model (Littell, Milliken, Stroup, \& Wofinger, 1996) is an extension of the standard general linear regression and is appropriate when the data consist of independent subjects or clusters, and the regression model for each subject or cluster can be assumed to be a random deviation from some population parameter estimate. The MMANOVA models separate means per group over time, where our interest focuses on (a) Group $\times$ Time interaction, which assesses whether the differences between groups vary over time, and (b) group effect, which assesses the difference between groups pooled across the longitudinal period. The MMANOVA is similar to repeated measures ANOVA in that it models the clustering of the repeated data but, unlike repeated measures ANOVA, offers more flexibility to model various covariance structures and accommodate missing data. In addition, the MMANOVA framework, as implemented in SPSS, allows withingroup and between-group contrasts to be investigated over various ranges of time.

A priori hypotheses involving multiple comparisons are specified below. Adjustments were not used for planned comparisons. However, for all tasks in which a priori hypotheses were not stated, omnibus $F$ tests, followed by post hoc comparisons, were conducted. All significance tests were two-tailed.

\section{Sample Descriptives and Trait Measures of Emotion and Emotion Regulation}

Sample descriptives and self-report questionnaires of trait emotion and emotion regulation were analyzed using a one-way ANOVA.

\section{Biological Vulnerability: RSA}

A $3 \times 2$ repeated measures ANOVA investigating the relationship between group and the two true baselines (group: BPD, SAD, $\mathrm{NC}$; task: films true baseline, imagery true baseline) indicated no Group $\times$ Task interactions, $F(2,56)=0.72, p=.49$. Similarly, a $3 \times 2$ repeated measures ANOVA investigating the relationship between group and the two vanilla baselines (group: BPD, SAD, $\mathrm{NC}$; task: films vanilla baseline, imagery vanilla baseline) indicated no Group $\times$ Task interactions, $F(2,56)=1.41, p=.25$. Therefore, true baselines were combined across the films and imagery conditions as well as the vanilla baselines across the films and imagery conditions. Differences between the three groups were then analyzed using a mixed model ANOVA, with epoch (i.e., eight epochs/30 s each) as the within-subjects factor and group (BPD, SAD, and $\mathrm{NC}$ ) as the between-subjects factor.

\section{Baseline Negative Emotional Intensity: SCR and Self-Report/VAS}

$S C R$. A $3 \times 2$ repeated measures ANOVA investigating the relationship between group and the two true baselines (group:
BPD, SAD, NC; task: films true baseline, imagery true baseline) indicated no Group $\times$ Task interactions, $F(2,54)=2.22, p=.12$. Similarly, a $3 \times 2$ repeated measures ANOVA investigating the relationship between group and the two vanilla baselines (group: $\mathrm{BPD}, \mathrm{SAD}, \mathrm{NC}$; task: films vanilla baseline, imagery vanilla baseline) indicated no Group $\times$ Task interactions, $F(2,54)=0.05$, $p=.95$. Therefore, true baselines were combined across the films and imagery conditions as well as the vanilla baselines across the films and imagery conditions. Differences between the three groups were then analyzed using a mixed model ANOVA, with epoch (i.e., eight epochs/30 s each) as the within-subjects factor and group (BPD, SAD, and NC) as the between-subjects factor.

Self-report/VAS. A composite score of negative emotion was computed (i.e., "VASNeg," consisting of items relaxed-tense, relaxed-anxious, calm-angry, unafraid-afraid, happy-sad, relieved-uptight, and contented-ashamed). Square-root transformations were used where violations of normality were violated. Differences in combined films and imagery true baseline VASNeg scores as well as combined films and imagery vanilla baseline VASNeg scores were then examined using independent samples $t$ tests.

\section{Emotional Reactivity: RSA, SCR, and Self-Report/VAS}

RSA and SCR. Emotional reactivity was operationalized as the difference between the mean RSA/SCR during the baseline prior to the emotion induction and the mean RSA/SCR during the emotion induction. As SC data are frequently positively skewed, square-root transformations were used as necessary (Venables \& Christie, 1980). A mixed model analysis of covariance (ANCOVA; with a total DSS score as the covariate) was run separately for each paradigm, with phase (baseline or film/ imagery) as the within-subjects factor and group (BPD, SAD, or $\mathrm{NC})$ as the between-subjects factor.

Self-report/VAS. Emotional reactivity was operationalized as the difference between the VAS rating during the baseline prior to the emotion induction and the VAS rating during the emotion induction. For the neutral tasks, emotional reactivity was operationalized as the difference between VASNeg during the baseline before the neutral task and VASNeg during the neutral task. The VAS data from the films and imagery procedures were analyzed using a mixed model ANOVA, with phase (baseline or film/ imagery) as the within-subjects factor and group (BPD, SAD, and NC) as the between-subjects factor.

\section{Results}

\section{Self-Report Measures}

A summary of the results for self-report measures appears in Table 3. One SAD participant was missing her DERS and STAXI data and, therefore, was not included in the analysis. Omnibus one-way ANOVAs indicated significant between-group differences in the total DERS score as well as all six DERS subscales, the AAQ, and the STAXI Trait Anger subscale. The BPD group scored higher than the NC group on all scales and subscales, and higher than SAD group on all but the AAQ Awareness subscale. A summary of the DSS appears in Table 4. As expected, the BPD group scored significantly higher on the DSS than the NC group 
Table 3

Mean Scores and Statistics on Self-Report Emotion and Emotion Regulation Measures

\begin{tabular}{|c|c|c|c|c|c|c|c|c|c|c|}
\hline \multirow[b]{2}{*}{ Measure } & \multicolumn{2}{|c|}{ BPD } & \multicolumn{2}{|c|}{$\mathrm{SAD}^{\mathrm{a}}$} & \multicolumn{2}{|c|}{$\mathrm{NC}$} & \multirow{2}{*}{$\frac{\text { Omnibus test }}{F(d f)}$} & \multirow{2}{*}{$\frac{\text { BPD vs. NC }}{t(d f)}$} & \multirow{2}{*}{$\frac{\text { BPD vs. SAD }}{t(d f)}$} & \multirow{2}{*}{$\frac{\text { SAD vs. NC }}{t(d f)}$} \\
\hline & $M$ & $S D$ & $M$ & $S D$ & $M$ & $S D$ & & & & \\
\hline DERS total & 114.65 & 20.62 & 87.79 & 19.36 & 71.00 & 13.19 & $29.93(2,56)^{* * * *}$ & $7.67(56)^{* * * *}$ & $4.66(56)^{* * * *}$ & $2.91(56)^{*}$ \\
\hline Nonacceptance & 18.7 & 4.74 & 15.53 & 6.08 & 11.00 & 4.01 & $11.88(2,56)^{* * * *}$ & $4.84(56)^{* * * *}$ & $1.98(56)^{*}$ & $2.81(56)^{*}$ \\
\hline Goal directed & 18.60 & 4.20 & 15.05 & 4.70 & 12.80 & 3.74 & $9.60(2,56)^{\text {***** }}$ & $4.36(56)^{* * * *}$ & $1.89(56)^{*}$ & $1.67(56)$ \\
\hline Impulse control & 18.10 & 5.82 & 10.05 & 3.54 & 9.65 & 2.90 & $24.54(2,56)^{\text {**** }}$ & $6.21(56)^{* * * * *}$ & $5.87(56)^{* * * * *}$ & $0.29(56)$ \\
\hline ER strategies & 25.85 & 6.98 & 17.89 & 5.65 & 13.25 & 3.94 & $25.73(2,56)^{* * * * * *}$ & $7.08(56)^{* * * * *}$ & $4.42(56)^{* * * * *}$ & $2.58(56)^{*}$ \\
\hline Awareness & 17.00 & 4.70 & 16.63 & 5.13 & 13.45 & 3.79 & $3.69(2,56)^{*}$ & $2.47(56)^{*}$ & $0.25(56)$ & $2.18(56)$ \\
\hline Clarity & 16.40 & 3.52 & 12.55 & 3.55 & 10.85 & 3.30 & $13.55(2,57)^{* * * * *}$ & $5.09(57)^{* * * *}$ & $3.49(57)^{* * *}$ & $1.56(57)$ \\
\hline AAQ total & 4.69 & 0.64 & 4.07 & 0.62 & 3.49 & 0.53 & $19.75(2,57)^{* * * * *}$ & $6.28(57)^{* * * *}$ & $3.20(57)^{* * * * *}$ & $3.08(57)^{* * *}$ \\
\hline STAXI-trait & 24.80 & 5.28 & 15.55 & 3.59 & 17.63 & 1.16 & $21.33(2,56)^{* * * *}$ & $6.23(56)^{* * *}$ & $4.77(56)^{* * * *}$ & $1.38(56)$ \\
\hline
\end{tabular}

Note. Higher scores indicate more difficulty in emotion regulation, experiential avoidance, and trait anger. $\mathrm{BPD}=$ borderline personality disorder; $\mathrm{SAD}=$ social anxiety disorder; $\mathrm{NC}=$ normal control; DERS $=$ Difficulties in Emotion Regulation Scale; AAQ = Acceptance and Action Questionnaire; STAXI-trait $=$ State-trait Anger Inventory.

${ }^{a}$ One SAD participant was missing her DERS and STAXI data and, therefore, was excluded from the analysis.

${ }^{*} p<.05 .{ }^{* *} p<.01 .{ }^{* * * *} p<.001$ ( $p$ values are bonferroni corrected).

across all film and imagery inductions and significantly higher than the SAD group in the sad and anger imagery inductions. There were no significant DSS differences between the SAD and $\mathrm{NC}$ groups on any film or imagery inductions.

\section{Biological Vulnerability: RSA True and Vanilla Baselines}

A summary of the results for the baseline analyses appears in Table 5. As predicted, the BPD group exhibited reduced RSA in the true and vanilla baselines compared with the NC group. Additionally, the BPD group demonstrated reduced RSA in the true and vanilla baselines compared with the SAD group. There were no significant differences in the true or vanilla baselines between the SAD and NC groups.

\section{Baseline Negative Emotional Intensity:}

\section{SCR and Self-Report/VAS True and Vanilla Baselines}

\section{$S C R$}

Results indicated that the BPD group exhibited a higher number of SCRs in the vanilla baseline and a trend toward a higher number of SCRs in the true baseline compared with the NC group. The
BPD group did not exhibit significantly higher SCRs compared with the SAD group in any of the baselines. The SAD group exhibited a higher number of SCRs in the true and vanilla baselines compared with the NC group.

\section{$V A S$}

As predicted, the BPD group reported significantly higher levels of negative emotion in the true and vanilla baselines compared with the NC group. There were no other significant differences.

\section{Emotional Reactivity: RSA, SCR, and Self-Report/VAS}

\section{$R S A$}

Results of the analysis of all films and Imagery Group $\times$ Phase interactions are reported in Tables 6 and 7. Only one significant difference emerged (see Figure 1). There was a significant difference in slopes between the BPD and SAD group in the sad film $(M=-0.43, S E=0.15), t(103.60)=$ $-2.89, p<.01$, such that the BPD group exhibited a significant increase in RSA from baseline to the sad film $(M=0.25, S E=$ $0.11, t(103.18)=-2.37, p<.05$, whereas the SAD group

Table 4

Mean Dissociation Scores and Statistics for Each Film and Imagery Task

\begin{tabular}{|c|c|c|c|c|c|c|c|c|c|c|}
\hline \multirow[b]{2}{*}{ Task } & \multicolumn{2}{|c|}{$\mathrm{BPD}$} & \multicolumn{2}{|c|}{ SAD } & \multicolumn{2}{|c|}{$\mathrm{NC}$} & \multirow{2}{*}{$\frac{\text { Omnibus test }}{F(d f)}$} & \multirow{2}{*}{$\frac{\mathrm{BPD} \text { vs. NC }}{t(d f)}$} & \multirow{2}{*}{$\frac{\text { BPD vs. SAD }}{t(d f)}$} & \multirow{2}{*}{$\frac{\mathrm{SAD} \text { vs. NC }}{t(d f)}$} \\
\hline & $M$ & $S D$ & $M$ & $S D$ & $M$ & $S D$ & & & & \\
\hline Sad film & 1.25 & 1.63 & 0.36 & 0.43 & 0.16 & 0.28 & $6.88(2,56)^{* * *}$ & $2.87(56)^{*}$ & $2.31(56)$ & $1.69(56)$ \\
\hline Anger film & 1.18 & 1.52 & 0.45 & 0.69 & 0.15 & 0.22 & $6.59(2,57)^{* *}$ & $3.20(57)^{*}$ & $1.98(57)$ & $1.84(57)$ \\
\hline Fear film & 1.25 & 1.63 & 0.36 & 0.43 & 0.16 & 0.28 & $6.88(2,56)^{* * *}$ & $2.87(56)^{*}$ & $2.31(56)$ & $1.69(56)$ \\
\hline Neutral film & 1.21 & 1.60 & 0.36 & 0.43 & 0.16 & 0.28 & $6.59(2,57)^{* * *}$ & $2.91(57)^{*}$ & $2.30(57)$ & $1.69(57)$ \\
\hline Sad imagery & 1.29 & 1.48 & 0.37 & 0.51 & 0.20 & 0.30 & $6.87(2,56)^{* *}$ & $3.16(56)^{*}$ & $2.58(56)^{*}$ & $1.29(56)$ \\
\hline Anger imagery & 1.81 & 1.87 & 0.53 & 0.72 & 0.33 & 0.44 & $9.16(2,56)^{* * * *}$ & $3.37(56)^{* *}$ & $2.79(56)^{*}$ & $1.10(56)$ \\
\hline Fear imagery & 1.70 & 1.78 & 0.66 & 0.85 & 0.38 & 0.53 & $6.87(2,56)^{* *}$ & $3.10(56)^{*}$ & $2.30(56)$ & $1.27(56)$ \\
\hline Neutral imagery & 1.70 & 1.78 & 0.66 & 0.85 & 0.38 & 0.53 & $6.87(2,56)^{* * *}$ & $3.10(56)^{*}$ & $2.30(56)$ & $1.27(56)$ \\
\hline
\end{tabular}

Note. $\quad \mathrm{BPD}=$ borderline personality disorder; $\mathrm{SAD}=$ social anxiety disorder; $\mathrm{NC}=$ normal control

${ }^{*} p<.05 .{ }^{* * *} p<.01 .{ }^{* * *} p<.001$ ( $p$ values are Games-Howell-corrected). 
Table 5

Baseline Film and Imagery Means and Statistics: RSA, SCR, and Self-Report

\begin{tabular}{|c|c|c|c|c|c|c|c|c|c|}
\hline \multirow[b]{2}{*}{ Measure } & \multicolumn{2}{|c|}{ BPD } & \multicolumn{2}{|c|}{ SAD } & \multicolumn{2}{|c|}{$\mathrm{NC}$} & \multirow{2}{*}{$\frac{\text { BPD vs. NC }}{t(d f), \text { Cohen's } d}$} & \multirow{2}{*}{$\frac{\text { BPD vs. SAD }}{t(d f), \text { Cohen's } d}$} & \multirow{2}{*}{$\frac{\text { SAD vs. NC }}{t(d f), \text { Cohen's } d}$} \\
\hline & $M$ & $S E$ & $M$ & $S E$ & $M$ & $S E$ & & & \\
\hline \multicolumn{10}{|l|}{$\operatorname{RSA}^{\mathrm{a}}\left(\mathrm{ms}^{2}\right)$} \\
\hline True baseline & 5.47 & 0.24 & 6.14 & 0.24 & 6.72 & 0.24 & $t(57)=-3.72,1.21^{* *}$ & $t(57)=-1.99,0.66$ & $t(57)=1.73,0.56$ \\
\hline Vanilla baseline & 5.37 & 0.23 & 6.14 & 0.23 & 6.59 & 0.23 & $t(57)=-3.84,1.23^{* * * *}$ & $t(57)=-2.43,0.78^{*}$ & $t(57)=-1.41,0.46$ \\
\hline \multicolumn{10}{|l|}{$\mathrm{SCR}^{\mathrm{a}, \mathrm{b}}$} \\
\hline True baseline & 1.69 & 0.44 & 2.17 & 0.45 & 0.79 & 0.45 & $t(54.38)=1.89,0.47$ & $t(54.38)=-1.01,0.25$ & $t(55)=2.86,0.72^{* *}$ \\
\hline Vanilla baseline & 2.78 & 0.37 & 2.32 & 0.38 & 1.00 & 0.38 & $t(53.92)=3.40,1.10^{* *}$ & $t(53.97)=0.87,0.29$ & $t(53.80)=2.50,0.82^{*}$ \\
\hline \multicolumn{10}{|l|}{$\operatorname{VAS}^{\mathrm{c}}$} \\
\hline True baseline & 4.77 & 0.51 & 4.01 & 0.46 & 3.41 & 0.31 & $t(38)=2.27,0.74^{*}$ & $t(38)=1.11,0.36$ & $t(38)=1.07,0.35$ \\
\hline Vanilla baseline & 4.69 & 0.51 & 3.81 & 0.41 & 2.78 & 0.34 & $t(38)=3.15,1.01^{* *}$ & $t(38)=1.36,0.44$ & $t(38)=1.96,0.63$ \\
\hline
\end{tabular}

Note. All significant differences and trends $(p=.07)$ are in bold. $\mathrm{RSA}=$ respiratory sinus arrhythmia; $\mathrm{SCR}=$ skin conductance response; $\mathrm{BPD}=$ borderline personality disorder; SAD = social anxiety disorder; $\mathrm{NC}=$ normal control; VAS = Visual Analogue Scale.

${ }^{a}$ Denominator degrees of freedom were derived from Sattherwaite approximation. ${ }^{b}$ Values refer to number of nonspecific fluctuations per minute. ${ }^{\mathrm{c}}$ Values are square-root transformed.

${ }^{*} p<.05 .{ }^{* * *} p<.01 .{ }^{* * * * *} p<.001$.

exhibited a decrease in RSA, although this change did not reach statistical significance $(M=-0.18, S E=0.11), t(104.05)=1.71$, $p>.05$. All other Group $\times$ Phase interactions in the films and imagery tasks were nonsignificant. ${ }^{1}$

\section{$S C R$}

Similar to the RSA data, results indicated that there were two significant Group $\times$ Phase interactions in the sad film (see Figure $1)$. There was a significant difference in slopes between the BPD and $\mathrm{NC}$ group $(M=-0.41, S E=0.19), t(93.68=2.16, p<.05$, such that the BPD group did not exhibit a significant change from baseline to the sad film $(M=-0.12, S E=0.13), t(93.62)=0.94$, $p>.05$, whereas the NC group exhibited a significant increase from baseline to the sad film $(M=0.28, S E=0.13), t(93.73)=$ $-2.10, p<.05$. Similarly, there was a significant difference in slopes between the BPD and SAD group $(M=-0.39, S E=0.19)$, $t(92.77)=2.09, p<.05$. Although the BPD group did not exhibit a significant change from baseline to the sad film $(M=-0.12$, $S E=0.13), t(93.62)=0.94, p>.05$, the SAD group exhibited a significant increase from baseline to the sad film $(M=0.27, S E=$ $0.13), t(91.94)=2.01, p<.05$. All other Group $\times$ Phase interactions in the films and imagery tasks were nonsignificant (see Footnote 1).

\section{$V A S$}

There were no significant Group $\times$ Phase interactions for any of the films or imagery tasks.

\section{Discussion}

Findings from this investigation offer partial support for Linehan's (1987) theory of emotion dysregulation in BPD. Three major findings emerged. First, BPD individuals exhibited lower basal RSA compared with the SAD and NC participants, indicating biological vulnerability to emotion dysregulation. Second, BPD individuals displayed high baseline negative emotional intensity, characterized by higher baseline electrodermal responding and self-reported negative emotions compared with the other two groups. Third, there were no indications of heightened reactivity in BPD on any index or in either emotion condition. Taken together, the baseline differences between the BPD and control groups coupled with the lack of differences in slope from baseline to emotional stress suggest that (a) BPD individuals are biologically vulnerable to emotion dysregulation and (b) emotion dysregulation in BPD is accounted for by high baseline emotional intensity and not by high reactivity. Indeed, these data seemingly conflict with clinical observations of emotional reactivity in BPD. Although clinical observations of high emotional intensity in BPD are often assumed to reflect high reactivity, these findings suggest that individuals meeting criteria for BPD are, in fact, not more "reactive" than nonclinical and socially anxious individuals. Rather, the extreme intensity of negative emotions often seen in BPD appears to be accounted for by the high starting point likely associated with persistent difficulties in regulation of negative affect.

\section{Biological Vulnerability}

Consistent with our hypothesis, BPD participants consistently demonstrated low basal RSA compared with the NC group in both the true and vanilla baselines. It is of interest that this finding conflicts with the null findings reported by Austin et al. (2007), who reported no significant basal RSA differences between BPD and NC. Reasons for this may be due to differences in the BPD participants between the two studies. Although we excluded participants with specific comorbid mental disorders (e.g., BPD, psychotic disorders, current substance dependence) in the present study, Austin and colleagues excluded BPD participants with any additional mental disorders. The BPD sample in the present study was likely drawn from a much more complex and severely challenged population.

\footnotetext{
${ }^{1}$ When analyses were rerun without controlling for dissociative state, findings did not change. (Data are available from Janice R. Kuo upon request.)
} 


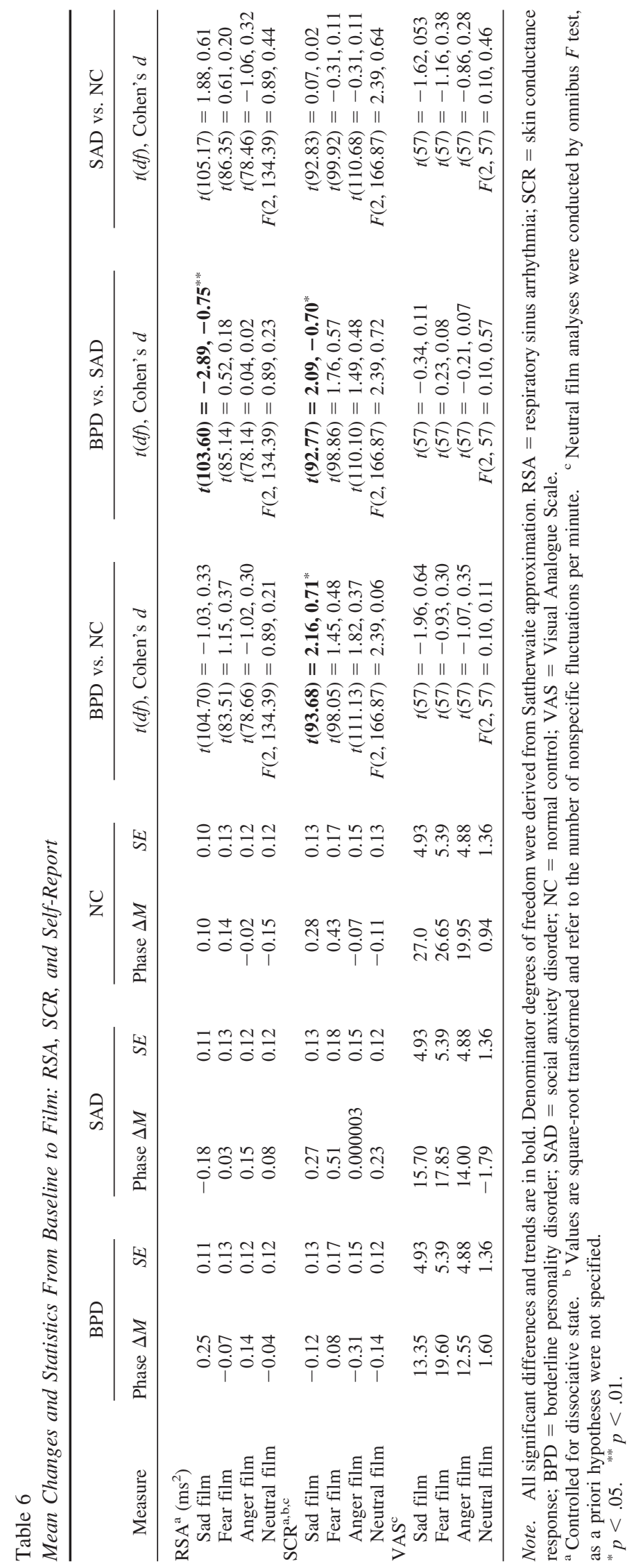




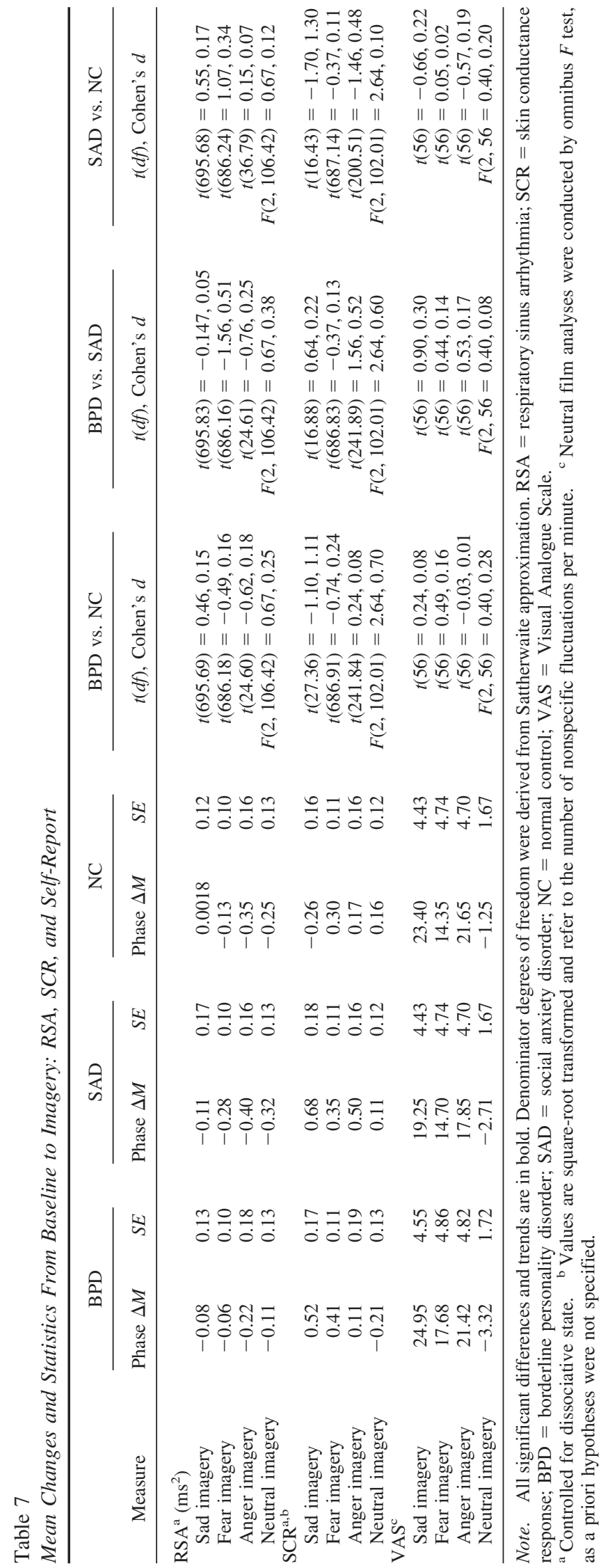

Additionally, the BPD group exhibited lower RSA compared with the SAD group in both the true and vanilla baselines, and there were no RSA differences in either of the baselines between the SAD and NC group. The differences in RSA between the BPD and SAD group is particularly compelling in that it suggests that reduced vagal tone is not a mere marker of psychopathology. Rather, these findings suggest that compromised parasympathetic functioning may be reflective of dimensional differences in emotion regulation capabilities between BPD and other clinical groups.

\section{Baseline Negative Emotional Intensity}

The BPD group also demonstrated high baseline negative emotional intensity as indicated by higher baseline SCR and selfreported negative emotions compared with the $\mathrm{NC}$ but not the $\mathrm{SAD}$ group. This finding was more robust for the self-report than for the electrodermal data. Although there were significant differences in self-reported negative emotion between the BPD and NC group across both baselines, the BPD group exhibited higher SCRs than the NC group in the vanilla baseline and a trend toward higher SCRs in the true baseline. Inspection of the mean SCR values showed that the BPD group had a higher number of SCRs in the vanilla baseline than the true baseline, whereas the NC group stayed relatively the same. Given that the vanilla baseline always followed the true baseline, it may be that the increased SCRs in the BPD group reflected increased distress from sitting for an extended period of time. Although the purpose of the vanilla baseline was to mitigate any such potential distress, it is possible that it was not effective in doing so. This may account for why the heightened baseline electrodermal activity (EDA) reported in this study conflicts with the previous reports of reduced EDA across slide viewing (Herpertz et al., 1999, 2000). It is possible that the slides functioned as a distraction from any potential distress induced by sitting over an extensive period, thus reducing EDA.

\section{Emotional Reactivity}

Our hypothesis of high emotional reactivity in BPD was not supported. Across both emotion conditions, the BPD group did not demonstrate greater self-reported or physiological changes in slope compared with the control groups. Inspection of the raw data also discounts the possible influence of a ceiling or floor (for RSA) effect, as self-reported negative emotion in the BPD group was less than 25 on a $0-100$ scale at baseline, and baseline SCR and RSA values for the BPD group were within the average range of reported scores in the literature (Dawson, Schell, \& Filion, 2007; Fukusaki, Kawakubo, \&Yamamoto, 2000).

A further unexpected finding also emerged. In the sad film, the BPD group exhibited a significant decrease in physiological reactivity from baseline to film compared with the NC and SAD groups. These findings are particularly interesting in that they suggest that the BPD group was not only less reactive than the SAD and NC groups but that they were more regulated and less aroused during the sad film, despite their self-reported increase in sadness. This was not the case for the SAD and NC groups, for whom increases in self-reported sadness were coupled with significant increases in electrodermal responding. A possible interpretation of the decoupling exhibited by the BPD group may be that, although this group did experience an increase in sadness 
Sad Film · RSA

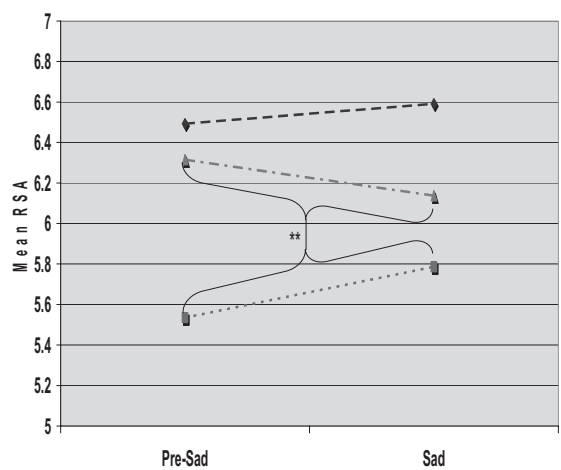

Sad Film - SCR

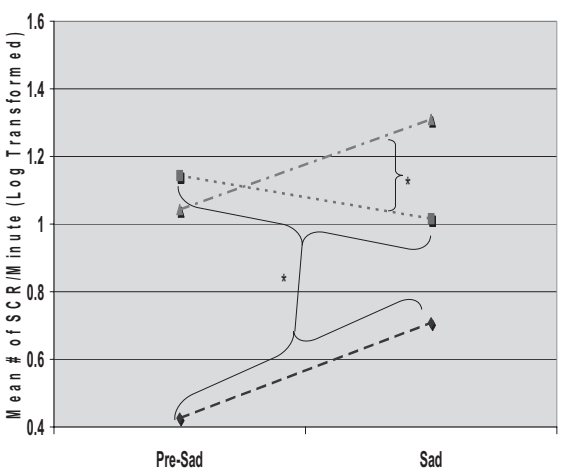

Sad Film - VAS

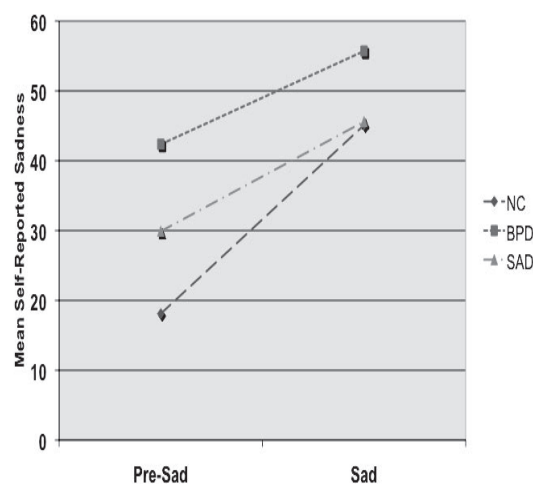

Figure 1. Sad Film group $\times$ Phase interactions. All significant differences and trends are in bold. RSA $=$ respiratory sinus arrhythmia; $\mathrm{SAD}=$ social anxiety disorder; $\mathrm{SCR}=$ skin conductance response; $\mathrm{VAS}=$ Visual Analogue Scale; $\mathrm{NC}=$ normal control; $\mathrm{BPD}=$ borderline personality disorder. ${ }^{*} p<.05 .{ }^{* *} p<.01$.

during the sad film, they were using implicit emotion regulation strategies to mitigate their emotional experiencing. Data from the emotion regulation literature suggest that within-subject changes in RSA may be reflective of emotion regulatory efforts, which may or may not correspond with increased positive emotional experiencing (Butler et al., 2006; Ingjaldsson, Laberg, \& Thayer, 2003). Therefore, the increase in RSA demonstrated by the BPD group may reflect engagement of emotion regulation strategies during the sad film.

Some limitations should be noted. First, controlling for medications, necessary due to possible dampening of physiological reactivity, limits the generalizability of our findings. In the present study, $80 \%$ of the BPD participants were not on medication, and $20 \%$ were only taking SSRIs. In a large longitudinal study of BPD individuals, $69 \%$ reported medication consultations in the first year of the study (Bender et al., 2006). In a recent randomizedcontrolled study on DBT (Linehan et al., 2006), 30\% of the BPD participants took more than just SSRI medication. Future larger scale studies should include participants with a wider range of medication use and compare differences in emotional processes between various medicated subgroups. Second, we did not exclude BPD participants with comorbid diagnoses. Given the high comorbid rates of BPD with other disorders, this decision increased the external validity, yet simultaneously decreased the internal validity of the study. However, although acknowledging the trade-off of compromising internal validity in the service of increasing external validity, adding the SAD control group mitigated some of the threat to internal validity.

A third limitation is that the personally relevant imagery condition was retrospective in nature. The participants knew how the script would unfold, and this knowledge likely influenced their emotional responding. This is of particular concern for the fear script, in which, in the actual event, being oblivious to the outcome is central to the experience of fear. Therefore, recalling the event retrospectively, for which the outcome was already known, likely mitigated the emotional responding. Nonetheless, the mere retrospective recall of an emotional event may not accurately reflect the actual intensity of emotional response during the time of the event.

The findings from this investigation, although informative, raise additional questions that will be important to address in future investigations. First, the relationship between emotional vulnerability and baseline emotional intensity warrants theoretical and empirical attention. Given that the we found evidence of emotional vulnerability and high baseline intensity in BPD, a question that follows is how these two constructs are related. Although Linehan's (1987) theory proposes that high emotional intensity is an outcome of vulnerability, direct empirical investigation of the conceptual and temporal relationship between these two constructs is needed. For instance, is intensity indeed an independent vulnerability factor? Does vulnerability lead to high baseline intensity (as proposed by Linehan's theory), or could it be that individuals experiencing high baseline intensity are more emotionally vulnerable? Addressing these questions in future investigations is crucial to further the understanding of the emotion dysregulation profile in BPD.

Some future directions are proposed. As indicated in the Method section, participants were not asked to report what strategies they might have implemented during the induction. Although dissociation was assessed, the possibility exists that participants engaged in other emotion regulation strategies during the induction period. Therefore, investigators of emotion processes in BPD may want to consider assessing for regulation strategies after using emotion inductions. However, although asking participants to report any strategies they might have used would allow for a better understanding of self-report and physiological patterns, doing so could potentially prompt participants to engage in various emotion regulation strategies that they otherwise would not have known to implement. If the purpose of the study is to investigate natural emotional processes, then this would pose a potential confound. Therefore, the decision whether to assess for emotion regulation strategies needs to be carefully weighed and considered in the context of the primary research question.

In conclusion, these findings have significant implications for the etiological and treatment-relevant models of BPD. As reviewed earlier, Linehan's (1993) theory encompasses a biosocial, developmental model of BPD, which proposes that BPD is the result of a transactional relationship between biological vulnerability to emotion dysregulation and an invalidating environment. It appears, therefore, that BPD individuals may not be more reactive to the invalidating environment but, rather, start off with a higher level of 
emotional intensity. Furthermore, although this study provides evidence for biological vulnerability in BPD and substantial literature report high rates of childhood sexual abuse (see Lieb et al., 2004; Murray, 1993, for a review) in this group (i.e., the epitome of an invalidating environment), the transactional relationship between these two factors on the subsequent development of BPD has not been directly examined. As such, it remains unclear whether the baseline intensity observed in this study is indeed a sequelae of vulnerability (as proposed by Linehan's model), or whether such intensity is the outcome of the chronic transaction between an emotionally vulnerable individual and an invalidating environment. Prospective, longitudinal studies are important to more rigorously substantiate Linehan's etiological model of BPD. In regards to clinical intervention, findings from this study offer specificity in the targeting of emotional reactions in BPD. Although emotional reactivity is often a primary treatment target in BPD, these findings suggest that skills that target emotional vulnerability and baseline intensity may be more useful.

\section{References}

Austin, M. A., Riniolo, T. C., \& Porges, S. W. (2007). Borderline personality disorder and emotion regulation: Insights from the polyvagal theory. Brain \& Cognition, 65, 69-76.

Barlow, D., Allen, L., \& Choate, L. (2004). Towards a unified treatment for emotional disorders. Behavior Therapy, 35, 205-230.

Battaglia, M., Ferini Strambi, L., Bertella, S., Bajo, S., \& Bellodi, L. (1999). First-cycle REM density in never-depressed subjects with borderline personality disorder. Society of Biological Psychiatry, 45, 10561058.

Battaglia, M., Ferini-Strambi, L., Smirne, S., Bernardeschi, L., \& Bellodi, L. (1993). Ambulatory polysomnography of never-depressed borderline subjects: A high-risk approach to rapid eye movement latency. Biological Psychiatry, 33, 326-334.

Beauchaine, T. (2001). Vagal tone, development, and Gray's motivational theory: Toward an integrated model of autonomic nervous system functioning in psychopathology. Development and Psychopathology, 13, 183-214.

Bender, D., Skodol, A., Pagano, M., Dyck, I., Grilo, C., Shea, M., et al. (2006). Prospective assessment of treatment use by patients with personality disorders. Psychiatric Services, 57, 254-257.

Berntson, G., Bigger, J., Eckberg, D., Grossman, P., Kaufmann, P., Malik, M., et al. (1997). Heart rate variability: Origins, methods, and interpretive caveats. Psychophysiology, 34, 623-648.

Berntson, G., Cacioppo, J., \& Quigley, K. (1991). Autonomic determinism: The modes of autonomic control, the doctrine of autonomic space, and the laws of autonomic constraint. Psychological Review, 98, 459-487.

Bernston, G., Quigley, K., Jang, J., \& Boysen, S. (1990). An approach to artifact identification: Application to heart period data. Psychophysiology, 27, 586-598.

Boutros, N., Torello, M., \& McGlashan, T. (2003). Electrophysiological aberrations in borderline personality disorder: State of the evidence. Journal of Neuropsychiatry and Clinical Neurosciences, 15, 145-154.

Butler, E., Wilhelm, F., \& Gross, J. (2006). Respiratory sinus arrhythmia, emotion, and emotion regulation during social interaction. Psychophysiology, 43, 612-622.

Cheavens, J., Rosenthal, M., Daughters, S., Novak, J., Kosson, D., Lynch, T., et al. (2005). An analogue investigation of the relationships among perceived parental criticism, negative affect, and borderline personality disorder features: The role of thought suppression. Behaviour Research and Therapy, 43, 257-268.

Clarkin, J., Widiger, T., Frances, A., Hurt, S., \& Gilmore, M. (1983).
Prototypic typology and the borderline personality disorder. Journal of Abnormal Psychology, 92, 263-275.

Cohen, H., Benjamin, J., Geva, A., Matar, M., Kaplan, Z., \& Kotler, M. (2000). Autonomic dysregulation in panic disorder and in post-traumatic stress disorder: Application of power spectrum analysis of heart rate variability at rest and in response to recollection of trauma or panic attacks. Psychiatry Research, 96, 1-13.

Cohen, H., Kotler, M., Matar, M., Kaplan, Z., Loewenthal, U., Miodownik, H., et al. (1998). Analysis of heart rate variability in posttraumatic stress disorder patients in response to a trauma-related reminder. Society of Biological Psychiatry, 44, 1054-1059.

Dawson, M., Schell, A., \& Filion, D. (2007). The electrodermal system. In J. Cacioppo, L. Tassinary, \& G. Berntson (Eds.), Handbook of psychophysiology (3rd ed., pp. 159-181). New York: Cambridge University Press.

Devlin, D. (Producer), \& Bill, T. (Director). (1980). My bodyguard [Motion picture]. United States: Fox Hills Video.

Donzella, B., Gunnar, M., Krueger, W., \& Alwin, J. (2000). Cortisol and vagal tone responses to competitive challenge in preschoolers: Associations with temperament. Developmental Psychobiology, 37, 209-220.

Driessen, M., Hermann, J., Stahl, K., Zwann, M., Meier, S., Hill, A., et al. (2000). Magnetic resonance imaging-based measurement of the hippocampus and the amygdala in women with borderline personality disorder and early traumatization. Archives of General Psychiatry, 57, $1115-1122$.

Ebner-Priemer, U., Badeck, S., Beckmann, C., Wagner, A., Feige, B., Weiss, I., et al. (2005). Affective dysregulation and dissociative experience in female patients with borderline personality disorder: A startle response study. Journal of Psychiatric Research, 39, 85-92.

Ebner-Priemer, U. W., Shaw-Welch, S., Grossman, P., Reisch, T., Linehan, M. M., \& Bohus, M. (2007). Psychophysiological ambulatory assessment of affective dysregulation in borderline personality disorder. Psychiatry Research, 150, 265-275.

First, M., Spitzer, R., Gibbon, M., \& Williams, J. (1995). Structured Clinical Interview for Axis I DSM-IV Disorders - Patient Edition (SCID$I / P)$. New York: Biometrics Research Department, New York State Psychiatric Institute.

First, M., Spitzer, R., Gibbons, M., Williams, J., \& Benjamin, L. (1996). User's guide for the Structured Clinical Interview for DSM-IV Axis II Personality Disorders (SCID-II). New York: Biometrics Research Department, New York State Psychiatric Institute.

Fischer, A. (2000). Gender and emotion: Social psychological perspectives. New York: Cambridge University Press.

Fowles, D., Christie, M., Edelberg, R., Grings, W., Lykken, D., \& Venables, P. (1981). Publication recommendations for electrodermal measurements. Psychophysiology, 18, 232-239.

Frances, A., Fyer, M., \& Clarkin, J. (1986). Personality and suicide. Annals of the New York Academy of Sciences, 487, 281-293.

Friedman, B., \& Thayer, J. (1998). Autonomic balance revisited: Panic anxiety and heart rate variability. Journal of Psychosomatic Research, 44, 133-151.

Fukusaki, C., Kawakubo, K., \& Yamamoto, Y. (2000). Assessment of the primary effect of aging on heart rate variability in humans. Clinical Autonomic Research, 10, 123-130.

Fyan, S., Goldberger, A., Pincus, S., Mietus, J., Lipsitz, L., \& Goldberger, A. (1994). Gender- and age-related differences in heart rate dynamics: Are women more complex than men? Journal of the American College of Cardiology, 24, 1700-1707.

Geller, J. (1986). In again, out again: Preliminary evaluation of a state hospital's worst recidivists. Hospital Community Psychiatry, 37, 386390.

Grant, B., Chou, S., Goldstein, R., Huang, B., Stinson, F., Saha, T., et al. (2008). Prevalence, correlates, disability, and comorbidity of DSM-IV borderline personality disorder: Results from the Wave 2 National 
Epidemiologic Survey on Alcohol and Related Conditions. Journal of Clinical Psychiatry, 69, 533-545.

Gratz, K., \& Roemer, L. (2004). Multidimensional assessment of emotion regulation and dysregulation: Development, factor structure, and initial validation of the Difficulties in Emotion Regulation Scale. Journal of Psychopathology and Behavioral Assessment, 26, 41-54.

Gross, J., \& Levenson, R. (1995). Emotion elicitation using films. Cognition \& Emotion, 9, 87-108.

Gurvits, I., Koenigsberg, H., \& Siever, L. (2000). Neurotransmitter dysfunction in patients with borderline personality disorder. The Psychiatric Clinics of North America, 23, 27-40.

Haines, J., Williams, C., Brain, K., \& Wilson, G. (1995). The psychophysiology of self-mutilation. Journal of Abnormal Psychology, 104, 471489

Hayes, S., Strosahl, K., Wilson, K., Bissett, R., Pistorello, J., Toarmino, D., et al. (2004). Measuring experiential avoidance: A preliminary test of a working model. The Psychological Record, 54, 553-578.

Hegerl, U., Stein, M., Mulert, C., Mergl, R., Olbrich, S., Dichgans, E., et al. (2007). EEG-vigilance differences between patients with borderline personality disorder, patients with obsessive-compulsive disorder and healthy controls. European Archives of Psychiatry and Clinical Neuroscience, 258, 137-143.

Henry, C., Mitropoulou, V., New, A., Koenigsberg, H., Silverman, J., \& Siever, L. (2001). Affective instability and impulsivity in borderline and bipolar II disorders: Similarities and differences. Journal of Psychiatric Research, 35, 307-312.

Herpertz, S., Kunert, H., Schwenger, U., \& Sass, H. (1999). Affective responsiveness in borderline personality disorder: A psychophysiological approach. American Journal of Psychiatry, 156, 1550-1556.

Herpertz, S., Schwenger, U., Kunert, H., Lukas, G., Gretzer, U., Nutzmann, J., et al. (2000). Emotional responses in patients with borderline as compared with avoidant personality disorder. Journal of Personality Disorders, 14, 339-351.

Herpertz, S., Werth, U., Lucas, G., Qunaibi, M., Schuerkens, A., Kunert, H., et al. (2001). Emotion in criminal offenders with psychopathy and borderline personality disorders. Archives of General Psychiatry, 58, 737-745.

Ingjaldsson, J., Laberg, J., \& Thayer, J. (2003). Reduced heart rate variability in chronic alcohol abuse: Relationship with negative mood, chronic thought suppression, and compulsive drinking. Society of Biological Psychiatry, 54, 1427-1436.

Jennings, J., Kamarck, T., Stewart, C., Eddy, M., \& Johnson, P. (1992). Alternate cardiovascular baseline assessment techniques: Vanilla or resting baseline. Psychophysiology, 29, 742-750.

Koenigsberg, H., Harvey, P., Mitropoulou, V., Schmeidler, J., New, A., Goodman, M., et al. (2002). Characterizing affective instability in borderline personality disorder. American Journal of Psychiatry, 159, 784788.

Koenigsberg, H., Kaplan, R., Gilmore, M., \& Cooper, A. (1985). The relationship between syndrome and personality disorder in DSM-III: Experience with 2,464 patients. American Journal of Psychiatry, 142, 207-212.

Levine, D., Marziali, E., \& Hood, J. (1997). Emotion processing in borderline personality disorders. Journal of Nervous \& Mental Disease, $185,240-246$

Lieb, K., Zanarini, M. C., Linehan, M. M., \& Bohus, M. (2004). Borderline personality disorder. The Lancet, 364, 453-461.

Linehan, M. (1982). Demographic data schedule (DDS). Unpublished manuscript, University of Washington.

Linehan, M. (1987). Dialectical behavior therapy for borderline personality disorder: Theory and method. Bulletin of the Menninger Clinic, 51, 261-276.

Linehan, M. (1993). Cognitive-behavioral treatment of borderline personality disorder. New York: Guilford Press.
Linehan, M., Comtois, K., Murray, A., Brown, M., Gallop, R., Heard, H., et al. (2006). Two-year randomized controlled trial and follow-up of dialectical behavior therapy vs therapy by experts for suicidal behaviors and borderline personality disorder. Archives of General Psychiatry, 63, 757-766.

Littell, R., Milliken, G., Stroup, W., \& Wofinger, R. (1996). SAS system for mixed models. Cary, NC: SAS Institute Inc.

Lovell, D. (Producer), \& Zeffirelli, F. (Director). (1979). The champ [Motion picture]. United States: MGM/Path Home Video.

Lyonfields, J., Borkovec, T., \& Thayer, J. (1995). Vagal tone in generalized anxiety disorder and the effects of aversive imagery and worrisome thinking. Behavior Therapy, 26, 457-466.

McGlashan, T., Grilo, C., Sanislow, C., Ralevski, E., Morey, L., Gunderson, J., et al. (2005). Two-year prevalence and stability of individual DSM-IV criteria for schizotypal, borderline, avoidant, and obsessivecompulsive personality disorders: Toward a hybrid model of axis II disorders. American Journal of Psychiatry, 162, 883-889.

Murray, J. (1993). Relationship of childhood sexual abuse to borderline personality disorder, posttraumatic stress disorder, and multiple personality disorder. The Journal of Psychology, 127, 657-676.

Ni, X., Chan, K., Bulgin, N., Sicard, T., Bismil, R., McMain, S., \& Kennedy, J. (2006). Association between serotonin transporter gene and borderline personality disorder. Journal of Psychiatric Research, 40, $448-453$.

Nutt, D., Argyropoulos, S., Hood, S., \& Potokar, J. (2006). Generalized anxiety disorder: A comorbid disease. European Neuropsychopharmacology, 16, 5109-5118.

Paris, J., Brown, R., \& Nowlis, D. (1987). Long-term follow-up of borderline patients in a general hospital. Comprehensive Psychiatry, 28, $530-535$.

Pitman, R., Orr, S., Forgue, D., de Jong, J., \& Claiborn, J. (1987) Pschophysiologic assessment of posttraumatic stress disorder imagery in Vietnam combat veterans. Archives of General Psychiatry, 44, 970-975.

Porges, S. (1995a). Cardiac vagal tone: A physiological index of stress. Neuroscience and Biobehavioral Reviews, 19, 225-233.

Porges, S. (1995b). Orienting in a defensive world: Mammalian modifications of our evolutionary heritage: A polyvagal theory. Psychophysiology, 32, 301-318.

Porges, S., Doussard-Roosevelt, J., \& Maiti, A. (1994). Vagal tone and the physiological regulation of emotion. Monograms of the Society for Research in Child Development, 59(2-3, Serial No. 240), 167-186.

Porges, S., Doussard-Roosevelt, J., Portales, A., \& Greenspan, S. (1996). Infant regulation of the vagal "brake" predicts child behavior problems: A psychobiological model of social behavior. Developmental Psychobiology, 29, 697-712.

Rechlin, T., Weis, M., Spitzer, A., \& Kaschka, W. (1994). Are affective disorders associated with alterations of heart rate variability? Journal of Affective Disorders, 32, 271-275.

Rosenthal, M., Cheavens, J., Lejuez, C., \& Lynch, T. (2005). Thought suppression mediates the relationship between negative affect and borderline personality disorder symptoms. Behaviour Research and Therapy, 43, 1173-1185.

Rosenthal, M., Gratz, K., Kosson, D., Cheavens, J., Lejuez, C., \& Lynch, T. (2008). Borderline personality disorder and emotional responding: A review of the research literature. Clinical Psychology Review, 28, 75-91.

Russell, J., Moskowitz, D., Zuroff, D., Sookman, D., \& Paris, J. (2007). Stability and variability of affective experience and interpersonal behavior in borderline personality disorder. Journal of Abnormal Psychology, 116, 578-588.

Sack, M., Hopper, J., \& Lamprecht, F. (2004). Low respiratory sinus arrhythmia and prolonged psychophysiological arousal in posttrauamatic stress disorder: Heart rate dynamics and individual differences in arousal regulation. Biological Psychiatry, 1, 284-290.

Samuels, J., Eaten, W., Bienvenu, J., Clayton, P., Brown, H., Costa, P., et 
al. (2002). Prevalence and correlates of personality disorder in a community sample. British Journal of Psychiatry, 180, 536-542.

Saxon, E., Utt, K., Bozman, R. (Producers), \& Demme, J. (Director). (1991). Silence of the lambs [Motion picture]. United States: Orion Pictures.

Schmahl, C., \& Bremner, D. (2006). Neuroimaging in borderline personality disorder. Journal of Psychiatric Research, 40, 419-427.

Schmahl, C., Elzinga, B., Ebner, U., Simms, T., Sanislow, C. Vermetten, E., et al. (2004). Psychophysiological reactivity to traumatic and abandonment scripts in borderline personality and posttraumatic stress disorders: A preliminary report. Psychiatry Research, 126, 33-42.

Schmahl, C., Vermetten, E., Elzinga, B., \& Bremner, J. (2003). Magnetic resonance imaging of hippocampal and amygdala volume in women with childhood abuse and borderline personality disorder. Psychiatry Research: Neuroimaging, 122, 109-115.

Skodol, A., Siever, L., Livesley, W., Gunderson, J., Pfohl, B., \& Widiger, T. (2002). The borderline diagnosis II: Biology, genetics, and clinical course. Biological Psychiatry, 51, 951-963.

Soloff, P., Lynch, K., \& Kelly, T. (2002). Childhood abuse as a risk factor for suicidal behavior in borderline personality disorder. Journal of Personality Disorders, 16, 201-214.

Soloff, P., Lynch, K., Kelly, T., Malone, K., \& Mann, J. (2000). Characteristics of suicide attempts of patients with major depressive episode and borderline personality disorder: A comparative study. American Journal of Psychiatry, 157, 601-608.

Spielberger, C., Krasner, S., \& Solomon, E. (1988). The experience, expression and control of anger. In M. P. Janisse (Ed.), Health psychology: Individual differences and stress (pp. 89-108). New York: Springer-Verlag.

Stein, K. F. (1996). Affect instability in adults with a borderline personality disorder. Archives of Psychiatric Nursing, 10, 32-40.

Stiglmayr, C., Grathwol, T., Linehan, M., Ihorst, G., Fahrenberg, J., \& Bohus, M. (2005). Aversive tension in patients with borderline personality disorder: A computer-based controlled field study. Acta Psychiatrica Scandinavica, 111, 372-379.

Stiglmayr, C., Shapiro, D., Stieglitz, R., Limberger, M., \& Bohus, M. (2001). Experience of aversive tension and dissociation in female patients with borderline personality disorder-a controlled study. Journal of Psychiatry Research, 35, 111-118.

Swartz, M., Blazer, D., George, L., \& Winfield, I. (1990). Estimating the prevalence of borderline personality disorder in the community. Journal of Personality Disorders, 4, 257-272.

Tebartz van Elst, L., Hesslinger, B., Thiel, T., Geiger, T., Haegele, K., Lemieux, L., et al. (2003). Frontolimbic brain abnormalities in patients with borderline personality disorder. A volumetric MRI study. Biological Psychiatry, 54, 163-171.

Thayer, J., Friedman, B., \& Borkovec, T. (1996). Autonomic characteristics of generalized anxiety disorder and worry. Biological Psychiatry $39,255-266$.

Torgersen, S., Kringlen, E., \& Cramer, V. (2001). The prevalence of personality disorders in a community sample. Archives of General Psychiatry, 58, 590-596.

Venables, P., \& Christie, M. (1980). Electrodermal activity. In I. Martin \& P. H. Venables (Eds.), Techniques in psychophysiology (pp. 3-67). Chichester, England: Wiley.

Widiger, T., \& Weissman, M. (1991). Epidemiology of borderline personality disorder. Hospital Community Psychiatry, 42, 1015-1021.

Williams, L., Sidis, A., Gordon, E., \& Meares, R. (2006). "Missing links" in borderline personality disorder: Loss of neural synchrony relates to lack of emotion regulation and impulse control. Journal of Psychiatry \& Neuroscience, 31, 181-188.

Yen, S., Zlotnick, C., \& Costello, E. (2002). Affect regulation in women with borderline personality disorder traits. Journal of Nervous \& Mental Diseases, 190, 693-696.

Yeragani, V., Balon, R., Pohl, R., Ramesh, C., Weinberg, P., \& Merlos, B. (1990). Decreased R-R variance in panic disorder patients. Acta Psychiatrica Scandinavica, 81, 554-559.

Zanarini, M., Frankenburg, F., Dubo, E., Sickel, A., Tikha, A., Levin, A., \& Reynolds, V. (1998). Axis I comorbidity of borderline personality disorder. The American Journal of Psychiatry, 155, 1733-1739.

Zanarini, M., Frankenberg, F., Hennen, J., \& Silk, K. (2003). The longitudinal course of borderline psychopathology: 6-year prospective follow-up of the phenomenology of borderline personality disorder. American Journal of Psychiatry, 160, 274-283.

Zisook, S., Goff, A., Sledge, P., \& Schuchter, S. (1994). Reported suicidal behavior and current suicidal ideation in a psychiatric outpatient clinic. Annals of Clinical Psychiatry, 6, 27-31.

Received October 17, 2008

Revision received April 7, 2009

Accepted April 13, 2009 